\title{
Analisis Tingkat Pengetahuan Wanita Usia Subur (Wus) Diwilayah Kerja Puskesmas Padasuka Kota Cimahi Tentang Kanker Payudara Sebelum Dan Sesudah Diberikan Penyuluhan Kesehatan
}

\author{
Novie E. Mauliku ${ }^{1)}$, Dzul Akmal ${ }^{2)}$ \\ ${ }^{1)}$ Program Studi Kesehatan Masyarakat Sekolah Tinggi Ilmu Kesehatan Jenderal Achmad Yani \\ Cimahi \\ ${ }^{2)}$ Program Studi Kesehatan Masyarakat Sekolah Tinggi Ilmu Kesehatan Jenderal Achmad Yani \\ Cimahi \\ Email : Noviemauliku@gmail.com
}

$\begin{array}{ll}\overline{\text { ARTICLE INFO }} & \\ \text { Accepted } & : 29 \text { April } 2021 \\ \text { Approve } & : \text { 05 Juni } 2021 \\ \text { Publish } & : \text { 30 Juni } 2021\end{array}$

\begin{abstract}
Currently, breast cancer no longer attacks adult women aged 30-50 years, but currently many breast cancer attacks young women / women of childbearing age and not a few adolescents aged 14 will suffer from breast cancer if they do not know how to detect cancer early. these breasts. The purpose of this study was to analyze the level of knowledge of women of childbearing age (WUS) in the working area of Puskesmas Padasuka, Cimahi City about breast cancer before and after being given health education. This study was a preexperimental study with a one group pretest-posttest design without control with a population of 11,407 WUS and a sample of 96 which was determined by the simple random sampling formula. The results showed that the difference in knowledge of women of childbearing age before and after being given health education with a $P$ value of 0.0001 . Seeing the results of the research found, there needs to be more attention given by the local health office and community health center regarding education and increasing knowledge of women of childbearing age related to breast cancer.
\end{abstract}

\section{Keywords: Knowledge, Fertile Age Women, Breast Cancer}

\begin{abstract}
Abstrak
Saat ini kanker payudara tidak lagi menyerang wanita dewasa yang memiliki usia $30-50$ tahun, tetapi kanker payudara saat ini banyak yang menyerang wanita usia muda / wanita usia subur dan tidak sedikit remaja yang berusia 14 akan menderita kanker payudara apabila tidak mengetahui cara mendeteksi dini kanker payudara tersebut.Tujuan penelitian ini untuk menganalisis tingkat pengetahuan wanita usia subur (WUS) di wilayah kerja Puskesmas Padasuka Kota Cimahi tentang kanker payudara sebelum dan sesudah diberikan penyuluhan kesehatan.Penelitian ini adalaha pre-eksperimental dengan rancangan one group pretestposttest without control dengan jumlah populasi 11.407 WUS dan sampel nya berjumlah 96 yang ditentukan dengan rumus Simpel random sampling.Hasil penelitian terlihat perbedaan pengetahuan wanita usia subur sebeluh dan sesudah diberikan penyuluhan kesehatan dengan nilai $\mathrm{P}$ Value adalah 0,0001 . Melihat hasil penelitian yang ditemukan, perlu adanya perhatian lebih yang diberikan oleh dinas kesehatan serta puskesmas setempat terkait dengan edukasi serta peningkatan pengetahuan wanita usia subur terkait dengan kanker payudara.
\end{abstract}


Kata Kunci : Pengetahuan, Wanita Usia Subur, Kanker Payudara

\section{PENDAHULUAN}

Ketika berbicara tentang kanker sama hal nya membicarakan salah satu penyebab kematian tertinggi didunia. Kanker sangat mematikan, salah satu kanker yang mematikan adalah kanker payudara. Kanker payudara umum terjadi pada wanita, kanker ini merupakan tumor yang yang sangat ganas yang tumbuh didalam jaringan payudara. Setiap tahunnya kanker payudara menyebabkan kematian lebih dari 185.000 wanita diseluruh dunia. Di negara maju, kematian akibat kanker payudara berkembang pesat, sekitar 43.500 kematian akibat kanker payudara terjadi di Negara Amerika Serikat. (Kemenkes RI, 2015).

Dinegara berkembang seperti Indonesia diperkirakan ada 100 penderita baru per 100.000 penduduk setiap tahunnya. Hal ini membuktikan bahwa dari 237 juta penduduk Indonesia, ada sekitar 237.000 penderita kanker baru setiap tahunnya. Semakin bertambahnya usia maka prevalensi kanker payudara ini akan semakin meningkat pula. Prevalensi kanker di Indonesia adalah 1,4 per 1000 penduduk. (Kemenkes RI, 2015).

Berdasarkan data kanker payudara berdasarkan wilayah, pada tahun 2019 provinsi Jawa Barat ditemukan 594 kasus kanker payudara. Hal ini membuktikan bahwa kanker payudara menyerang hampir disemua wilayah di indonesia, dan Forum
Bandung Sehat juga mencatat kejadian kanker payudara menyerang wanita dan tidak mengenal kelompok usia. (Dinkes Prov. Jabar, 2019) Pada saat ini kanker payudara tidak lagi menyerang wanita dewasa yang memiliki usia 30 -50 tahun, tetapi kanker payudara saat ini banyak yang menyerang wanita usia muda / wanita usia subur dan tidak sedikit remaja yang berusia 14 akan menderita kanker payudara apabila tidak mengetahui cara mendeteksi dini kanker payudara tersebut. (Mboi, 2014).

Saat ini beberapa di daerah Jawa Barat sangat aktif mengkampanyekan melawan kanker payudara salah satunya adalah Kota Cimahi. Tahun 2020 Pemerintah Kota Cimahi menggelar layanan Tes Inspeksi Visual Asam Asetat (IVA Tes) selama Februari 2020 di Puskesmas se-Kota Cimahi. Hal ini diharapkan masyarakat terutama perempuan bisa deteksi dini kanker serviks dan juga kanker payudara dan menjaga kesehatannya agar tidak terjangkit penyakit tersebut.Gebyar layanan IVA Test berlangsung dalam rangkaian peringatan Hari Kanker Sedunia Dinas Kesehatan (Dinkes) Kota Cimahi bekerjasama dengan Yayasan Kanker Indonesia (YKI) Cabang Kota Cimahi, IDI Kota Cimahi, dan IBI Kota Cimahi menggelar layanan di Puskesmas Cimahi Tengah dan Bidan Delima di 
Padasuka. Kegiatan digelar dalam rangka peringatan Hari Kanker Sedunia yang diperingati tiap tanggal 4 Februari. Kegiatan terdiri dari workshop tentang kanker serviks dan payudara, dan pemeriksaan IVA Tes yang diikuti sekitar 150 orang. Kegiatan ini menjadi upaya bersama untuk pencegahan kanker terutama bagi perempuan melalui deteksi dini kanker serviks dan kanker payudara. Diharapkan dapat membantu meningkatkan pengetahuan dan kesadaran warga untuk mendeteksi kanker secara dini.Pencegahan kanker bukan hanya tugas dinas tapi butuh kerjasama dan dukungan semua pihak terutama masyarakat sehingga memiliki pengetahuan, kemauan, dan kemampuan meningkatkan kesehatannya, sehingga diharapkan angka kesakitan akibat kanker dapat diturunkan secara signifikan. Kegiatan Deteksi Dini Kanker Leher Rahim dan Kanker Payudara dengan metoda IVA test dan Sadanis dilaksanakan pada 2 s.d 27 April 2018 di 13 Puskesmas.Dari 1542 WUS yang diperiksa pada Triwulan II 2018, sebanyak 7 orang hasil IVA test posistif.Dengan adanya kegiatan IVA Test dan SADANIS ini, diharapkan agar kasus kanker payudara dan kanker serviks mengalami penurunan dikemudian hari. Dan warga Kota Cimahi yang hasil pemeriksaan IVA test positif bisa dilakukan pengobatan lebih awal agar tidak menjadi stadium
lanjut.(Dinkes Kota Cimahi, 2020). Akan tetapi meningkatkan pengetahuan bukanlah perkara mudah, apalagi meningkatkan pengetahuan terkait kanker payudara. Pengetahuan dipengaruhi oleh banyak faktor, antara lain faktor usia dan paparan informasi. (Notoatmodjo, 2014).

Berdasarkan permasalahan ini maka dirumuskan tujuan penelitian ini yaitu Analisis tingkat pengetahuan wanita usia subur (WUS) di wilayah kerja Puskesmas Padasuka Kota Cimahi tentang kanker payudara sebelum dan sesudah diberikan penyuluhan kesehatan.

\section{METODE}

Penelitian ini adalah preeksperimental dengan rancangan one group pretest-posttest without control yaitu peneliti melakukan observasi sebelumnya, lalu melihat perubahan-perubahan yang terjadi setelah adanya perlakuan. Desain ini dilakukan tanpa adanya kelompok kontrol. Sebelum dilakukan intervensi, responden diberikan kuesioner untuk pengukuran pengetahuan awal (pretest), kemudian responden diberikan intervensi dalam bentuk promosi kesehatan. Promosi kesehatan berlangsung selama 30 menit yang terdiri dari ceramah dan juga 30 menit yang terdiri dari diskusi kelompok. Saat diskusi kelompok diberi pendampingan di setiap peserta agar 
memahami setiap informasi yang diterima. Setelah itu kelompok dibagi menjadi kelompok kecil dan diberikan intervensi kembali dikelompok kecil tersebut. Setelah diberikan intervensi, responden diberikan kuesioner kembali untuk pengukuran pengetahuan akhir (posttest). Pada saat pengisian kuesioner kembali diberi pendampingan agar responden mengisi dengan baik dan jika ada yang kurang jelas bisa ditanyakan kepada tutor yang mendampingi. Hal ini dilakukan untuk mengetahui pengaruh pengetahuan wanita usia subur (WUS) di wilayah kerja Puskesmas Padasuka Kota Cimahi tentang kanker payudara sebelum dan sesudah diberikan penyuluhan kesehatan. (Riyanto, 2011).Populasi dari penelitian ini adalah seluruh WUS di wilayah kerja Puskesmas Padasuka Kota Cimahi dengan total WUS sebanyak 11.407. Disisi lain jumlah sampel adalah 96, penentuan sampel menggunakan rumus Simpel random sampling.Variabel penelitian ini adalah pengetahuan, Pengetahuan responden diukur dalam 2 waktu yang berbeda yaitu pengetahuan sebelum diberi penyuluhan dan pengetahuan setelah diberi penyuluhan.

\section{HASIL DAN PEMBAHASAN}

Tabel 1 Gambaran Pengetahuan Wanita Usia Subur (WUS) Tentang Kanker Payudara Sebelum Di Berikan Penyuluhan Kesehatan

\begin{tabular}{ccc}
\hline Pengetahuan & Jumlah & Presentase \\
\hline Kurang Baik & 60 & $62,5 \%$ \\
\hline Baik & 36 & $37,5 \%$ \\
\hline Total & 96 & $100 \%$
\end{tabular}

Hasil analisis univariat pengetahuan responden tentang kanker payudara sebelum penyuluhan kesehatan hanya terdapat 36 responden $(37,5 \%)$ yang memiliki pengetahuan baik tentang kanker payudara. Responden dapat dikatakan memiliki pengetahuan baik ketika responden dapat menjawab benar $\geq 75 \%$ dari total item pertanyaan. Responden cenderung mempunyai pengetahuan cukup yaitu sebanyak 60 responden $(62,5 \%)$ dikarenakan responden memiliki tingkat pendidikan yang rendah, dan kurangnya informasi atau penyuluhan kesehatan dari puskesmas setempat selama ini sehingga membuat pengetahuan responden kurang baik tentang kanker payudara. Hal ini diakui oleh sebagian besar responden yang mengatakan bahwa sebelumnya belum pernah ada yang memberikan informasiataupenyuluhankesehatanmengen aikanker payudara. Salah satu faktor yang 
dapat mempengaruhi pengetahuan adalah pendidikan dan informasi, tidak dapat dipungkiri bahwa makin tinggi pendidikan seseorang semakin mudah pula mereka untuk menerima informasi begitu juga sebaliknya jika tingkat pendidikan seseorangrendah maka akan menghambat perkembangan sikap seseorang terhadap penerimaan informasi (Notoatmodjo, 2018).

Sebelum dilakukan penyuluhan kesehatan, pertanyaan pengetahuan yang paling sedikit dijawab benar adalah mengenai cara melindungi diri dari kanker payudara,pertanyaan ini hanya dapat dijawab benar oleh 7 dari 96 responden yang ada. Namun, setelah penyuluhan kesehatan jumlah responden yang menjawab benar meningkat dari 7 responden yang menjawab benar menjadi 79 responden yang menjawab benar.

Pertanyaan pengetahuan selanjutnya yang paling sedikit dijawab benar adalah mengenai tanda/gejala terkena kanker payudara, pertanyaan ini hanya dapat dijawab benar oleh 8 dari 96 responden yang ada namun, setelah promosi kesehatan jumlah responden yang menjawab benar meningkat dari 8 responden yang menjawab benar menjadi 82 responden yang menjawabbenar.

Tabel 2 Gambaran Pengetahuan Wanita Usia Subur (WUS) Tentang Kanker Payudara Setelah Di Berikan Penyuluhan Kesehatan

\begin{tabular}{ccc}
\hline Pengetahuan & Jumlah & Presentase \\
\hline Kurang Baik & 10 & $10,4 \%$ \\
\hline Baik & 86 & $89,6 \%$ \\
\hline Total & 96 & $100 \%$
\end{tabular}

Hasil analisis univariat pengetahuan respondententangkanker payudara setelah penyuluhan keseharan terdapat 86 responden $(689, \%)$ yang memiliki pengetahuan baik tentang kanker payudara. Peningkatan jumlah responden yang memiliki pengetahuan baik dari 36 responden $(37,5 \%)$ menjadi 86 responden $(89,6 \%)$ dapat terjadi karena adanya pemberian informasi melalui penyuluhan kesehatan dan metode promosi kesehatan yang digunakan sesuai kebutuhan sehingga, tujuan promosi kesehatan yaitu untuk meningkatkan pengetahuan terjadi secara optimal (Notoatmodjo, 2018).

Metode penyuluhan kesehatan yang digunakan dalam penelitian ini adalah metode massa dengan ceramah umum dan metode kelompok dengan diskusi kelompok, metode promosi kesehatan secara massa dipakai untuk mengkomunikasikan pesan-pesan kesehatan yang ditujukan kepada masyarakat yang sifatnya (Notoatmodjo, 
2018) sehingga, peneliti menggunakan metode penyuluhan kesehatan ini karena responden berjumlah 96 orang. Peneliti menjelaskan mengenai pengertian kanker payudara, gejala kanker payudara, tanda tanda kanker payudara, gejala klinis kanker payudara, pencegahan kanker payudara, pengobatan kanker payudara dan langkahlangkah pencegahan kanker payudara untuk semua responden. Penyuluahn kesehatan Menggunakan media slide selama 60 menit dilanjutkan dengan diskusikelompok.

Diskusi kelompok digunakan dengan pertimbangan agar tujuan dari penyuluhan kesehatan dapat tercapai dengan efektif. Responden dibagi menjadi 10 kelompok yang dalam satu kelompok terdiri 9 responden dan didampingi oleh satu orang pemimpin diskusi. Diskusi diatur agar tiap kelompok duduk melingkar dan saling berhadapan termasuk pimpinan diskusi, hal ini dibuat agar tidakmenimbulkankesan ada taraf yang lebih tinggi antara pimpinan diskusi dan responden (Notoatmodjo, 2018).

Media yang digunakan ketika diskusi kelompok adalah media cetak. Menurut (Notoatmodjo, 2018) media cetak memiliki fungsi utama yaitu untuk memberikan informasi. Media cetak yang digunakan dalam penelitian ini berbentuk leaflet agar membantu arah diskusi dalam memberikan informasi dan juga mempermudah pemahamaan responden akan kanker payudara. Media cetak juga digunakan dalam penelitian penelitian Sugandi, Wahyuni (2015) dan menghasilkan peningkatan jumlah responden yangberpengetahuanbaikdari14responden(3 7,8\%)menjadi27responden

(73\%).Responden yang memiliki pengetahuan baik setelah promosi kesehatan berjumlah 21 responden dari total 25 responden, hal ini dapat terjadi bahwa tidak semua responden sekaligus memiliki pengetahuan yang baik karena pada waktu pengindraan sampai menghasilkan pengetahuan sangat dipengaruhi oleh intensitas perhatian dan npersepsi responden yang berbeda-beda terhadap objek (Notoatmodjo,2018). 
Tabel 3 Pengaruh Penyuluhani Kesehatan Terhadap Pengetahuan Wanita Usia Subur (WUS)

Tentang Kanker Payudara

\begin{tabular}{|c|c|c|c|c|c|}
\hline Variabel & Mean & SD & SE & P Value & $\mathbf{N}$ \\
\hline Pengetahuan Sebelum & 11,92 & 2,51 & 0,50 & \multirow{3}{*}{0,0001} & \multirow{3}{*}{96} \\
\hline Penyuluhan Kesehatan & & & & & \\
\hline Pengetahuan Setelah & 15,52 & 2,05 & 0,42 & & \\
\hline Penyuluhan Kesehatan & & & & & \\
\hline
\end{tabular}

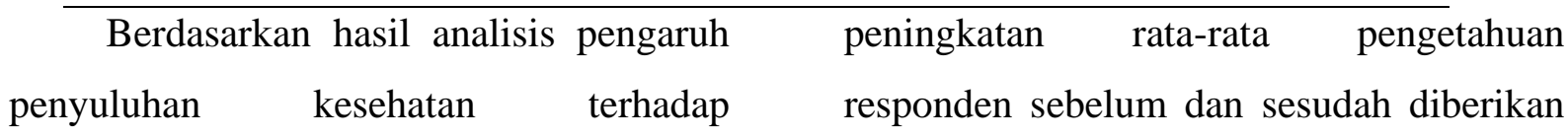

pengetahuan tentang kanker payudara pada wanita usia subur terjadi peningkatan jumlah responden yang memiliki pengetahuan baik sebelum dan sesudah penyuluhan kesehatan. sebelum penyuluhan kesehatan terdapat 36 responden $(37,5 \%)$ yang memiliki pengetahuan baik dan setelah penyuluhan kesehatan jumlah responden yang memiliki pengetahuan baik meningkat menjadi 86 responden $(89,6 \%)$.

Hasil uji bivariat didapatkan bahwa rata-rata skor pengetahuan responden sebelum penyuluhan kesehatan 11,92 dengan standar deviasi 2,51 dan skor pengetahuan responden setelah promosi kesehatan adalah 15,52 dengan standar deviasi 2,05 hasil uji statistik didapatkan pvalue $=0,0001$ maka dapat disimpulkan terdapat perbedaan yang signifikan yaitu penyuluhan kesehatan.

Hasil penelitian ini sesuai dengan hasil penelitian yang dilakukan oleh Sugandi, Wahyuni, (2015) yang menunjukan terdapat pengaruh signifikan promosi kesehatan menggunakan media cetak (sticker) terhadap peningkatan pengetahuan pedagang burung dengan $\mathrm{p}$ value $=0,002$. Disisi lain hasil penelitian yang dilakukan oleh Syatiawati dkk, (2017) menunjukan bahwa promosi kesehatan melalui metode ceramah dan diskusi efektif terhadap peningkatan pengetahuan kesehatan reproduksi pada siswa kelas 7 SMP dengan $\mathrm{p}$-value $=0,001$. Penelitian yang dilakukan oleh Stauri (2015) juga menunjukan terdapat peningkatan rata-rata pengetahuan penggunaan APD setelah diberikan pendidikan kesehatan. Rata-rata tingkat pengetahuan sebelum diberikan 
pendidikan kesehatan yaitu 7,40 (30,4\%) masuk ke dalam kategori pengetahuan kurang dan setelah diberikan pendidikan kesehatan rata-rata tingkat pengetahuan menjadi $17,67(78,2 \%)$ masuk ke dalam kategori pengetahuan baik, p-value $=0,0001$ yang berarti terdapat perbedaan signifikan pengetahuan Alat Pelindung Diri sebelum dan sesudah diberikan pendidikan kesehatan.

Penelitian lain yang dilakukan oleh Siregar (2014) juga menunjukan terdapat peningkatan rata-rata pengetahuan pada pekerja las sebelum dan sesudah dilakukan promosi kesehatan mengenai Alat Pelindung Diri dengan metode ceramah yaitu 11.05 sebelum dilakukan promosi kesehatan menjadi 15.71 setelah dilakukan promosi kesehatan, $p$-value $=0,0001$ yang berarti terdapat perbedaan signifikan pengetahuan Alat Pelindung Diri sebelum dan sesudah diberikan penyuluhan dengan metode ceramah dan diskusikelompok.Pengetahuan seseorang sebagian besar didapat melalui indera pendengaran dan indera penglihatan (Notoatmodjo, 2018) sehingga, dengan adanya kedua metode penyuluhan kesehatan yang dilakukan oleh peneliti yang metode ceramah dengan media slide serta video dan metode diskusi kelompok dengan media leaflet yang mengandalkan penggunaan indera pendengaran dan indera penglihatan sangatmemungkinkan pengetahuan responden meningkat setelah diberikan penyuluhan kesehatan.

Menurut Silberman dalam Bahruddin, (2015) menjelaskan bahwa belajar membutuhkan keterlibatan mental. Belajar dengan cara mendengarkan saja akan membuat seseorang menjadi lupa, dengan melihat akan membuat seseorang mengingat sedikit, dan dengan melakukan diskusi akan membuat seseorang mengingat juga paham terhadap apa yang disampaikan, metode yang dilakukan dalam penelitian ini yaitu metode ceramah dan diskusi kelompok yang merupakan bentuk belajar dengan cara mendengarkan, melihat juga melakukan diskusi dan berdasarkan teori yang ada penelitian ini dapat membuat seseorang mengingat materi atau pengetahuan baru yang diberikan juga memahaminya sehingga, hal ini dapat menjadi faktor yang membuat pengetahuan responden meningkat setelah diberikan penyuluhan kesehatan.

\section{KESIMPULAN}

Terdapat perbedaan yang signifikan pada peningkatan rata - rata pengetahuan wanita usia subur sebelum dan sesudah diberikan penyuluhan kesehatan tentang kanker payudara. Hal ini terlihat dari ratarata skor pengetahuan wanita usia subur sebelum diberikan penyuluhan kesehatan adalah 11.92 dengan standar deviasi 2,51 
dan rata - rata skor pengetahuan wanita usia subur setelah diberikan penyuluhan kesehatan adalah 12,52 dengan standar deviasi 2,05, terlihat perbedaan pengetahuan wanita usia subur sebeluh dan sesudah diberikan penyuluhan kesehatan dengan nilai P Value adalah 0,0001 .

\section{SARAN}

Melihat hasil penelitian yang ditemukan, perlu adanya perhatian lebih yang diberikan oleh dinas kesehatan serta puskesmas setempat terkait dengan edukasi serta peningkatan pengetahuan wanita usia subur terkait dengan kanker payudara. Hal ini perlu dilakukan agar kejadian kanker payudara dapat dicegah sedini mungkin.

\section{DAFTAR PUSTAKA}

Budiman dan Riyanto, A. 2013. Kapita Selekta Kuesioner: Pengetahuan dan Sikap dalam Penelitian Kesehatan. Jakarta: Salemba Medika

Bahruddin dan Wahyuni. 2015. Teori Belajar dan Pembelajaran. Yogyakarta: Ar- ruzz Media.

Kemenkes. RI. Buletin Jendela Data dan Informasi Kesehatan: Situasi Penyakit Kanker. Jakarta: Kemenkes RI;2015.

Kemenkes. RI. Infodatin: Bulan Peduli Kanker Payudara. Jakarta: Kemenkes RI;2016.

Kemenkes. RI. Panduan Penatalaksanaan Kanker Payudara. Jakarta: Kemenkes RI; 2013.

Kemenkes. RI. Panduan Nasional Penanganan Kanker Payudara. Komite Nasional Penanggulangan Kanker (KPKN). (2015).
Mboi, N. (2014). Panduan Praktik Klinis Bagi Dokter di Fasilitas Pelayanan Kesehatan Primer. Menteri Kesehatan Republik Indonesia, 332 $-337$.

Narsih U et al. Pendidikan dan Pelatihan tentang SADARI bagi Remaja Putri. Jurnal Paradharma. 2017

Notoatmodjo, S. 2014. Promosi Kesehatan dan Perilaku Kesehatan. Edisi Revisi. Jakarta. Rineka Cipta.

Notoadmodjo, S. 2018. Promosi Kesehatan Teori dan Aplikasi. Jakarta: Rineka Cipta.

Novasari DH, dkk. Hubungan Pengetahuan, Sikap dan Paparan Media Informasi dengan Praktik Pemeriksaan Payudara Sendiri (Sadari) pada Santriwati Pondok Pesantren Al Ishlah Tembalang Semarang Tahun 2016. Jurnal Kesehatan Masyarakat. 2016; 4 (4):186-194.

Novitasary, DN ; Mayulu, N ; Kawengian, $\mathrm{S}:$ Hubungan Antara Aktivitas Fisik Dengan Obesitas Pada Wanita Usia Subur Peserta Jamkesmas Di Puskesmas Wawonasa Kecamatan Singkil Manado. Jurnal 3-Biomedik (eBM), Volume 1 Nomor 2, Juli 2013

Profil Kesehatan Dinas Kesehatan Provinsi Jawa Barat Tahun 2019.

Profil Kesehatan Dinas Kesehatan Kota Cimahi Tahun 2020.

Riyanto, A.2011. Aplikasi Metodologi Penelitian Kesehatan.Yogyakarta: Nuha Medika.

Riyanto, A.2013a. Statistik Deskriptif untuk Kesehatan.Yogyakarta:Nuha Medika.

Riyanto, A. 2013b. Statistik Inferensial Untuk Analisa Data Kesehatan. yogyakarta: Nuha Medika.

Siregar, G.P.2014. Pengaruh Penyuluhan dengan Metode Ceramah dan Diskusi Kelompok Tentang Alat Pelindung DiriTerhadap Peningkatan Perilaku Pekerja Las Di Kecamatan Percut Sei Tuan 
Tahun 2013.Jurnal Ilmiah PANMED Vol.8 No.3:272-276.

Sugandi, Wahyuni. 2015. Promosi Kesehatan Dengan Media Sticker Terhadap Tingkat Pengetahuan, Sikap Dan Praktik Penggunaan Masker Pada Pedagang Burung di Pasar Depok Kota
Surakarta.Indonesian Journal On Medical Science, Vol.2 No.2:92-98. Syatiawati, dkk. 2017. Efektivitas Metode Promosi Kesehaan dalam Meningkatkan Pengetahuan Tentang Kesehatan Reproduksi Siswi SMP Negeri. Bandung Meeting on Global Medicine \& Health (BaMGMH), Vol. 1 No. 1: 42-48. 